\title{
Urdiduras da condição social feminina em contos maravilhosos: uma análise comparativa de Rumpelstilsequim e A moça tecelã
}

Warps of the female social condition in wonderful tales: a comparative analysis of Rumpelstiltskin and The weaver girl

\section{Gisele Gemmi Chiari ${ }^{{ }^{I}}$}


RESUMO: A proposta do estudo é comparar a versão de Rumpelstilsequim (2014, p. 259261), escrita pelos irmãos Grimm, com o conhecido texto de Marina Colasanti, A moça tecelã (2006, p. 9-14). Além das simetrias mais perceptíveis entre os dois contos, como a presença do maravilhoso e a prática da tecelagem envolvendo as protagonistas, serão consideradas as diferenças entre ambos com base numa perspectiva histórico-social. Nesse sentido, e em diálogo com Jack Zipes (1993, p. 43-60), comentaremos como o sistema patriarcal e o desenvolvimento do capitalismo e da indústria têxtil estão refletidos nas ações das personagens. Consideraremos também a importância do conteúdo simbólico das narrativas, aspecto inerente e essencial à compreensão do conto maravilhoso.

PALAVRAS-CHAVES: Conto maravilhoso; Condição social feminina; Irmãos Grimm; Marina Colasanti;

ABSTRACT: The purpose of the study is to compare the version of Rumpelstilsequim (2014, p. 259-261), written by the Grimm brothers, with the well-known text by Marina Colasanti, The Weaving Girl (2006, p. 9-14). In addition to the most noticeable symmetries between the two tales, such as the presence of the wonderful and the practice of weaving involving the protagonists, will be considered the differences between both based on a historical-social perspective. In this sense, and in dialogue with Jack Zipes (1993, p. 43-60), we will comment on how the patriarchal system and the development of capitalism and the textile industry are reflected in the actions of the characters. We will also consider the importance of the symbolic content of the narratives, an inherent and essential aspect for understanding the wonderful tale.

KEYWORDS: Wondertale; Female social condition; Brothers Grimm; Marina Colasanti; 
No conto maravilhoso, o sobrenatural é naturalizado². Geralmente, os espaços são lugares desconhecidos ou não nomeados e o tempo indeterminado. Os conflitos existentes no fantástico, como a oposição entre o natural e o sobrenatural, não estão presentes, pois no âmbito do maravilhoso tudo é possível ${ }^{3}$. Assim, encantamentos, milagres, metamorfoses e outros acontecimentos mágicos ocorrem sem que os personagens da história os interroguem, considerando-os parte natural da existência (ROAS, 2014, p. 34). Com base em tal assertiva, consideramos que Rupelstiltsequim e A moça tecelã podem ser considerados contos maravilhosos, o primeiro, acatado como um exemplo de conto tradicional ${ }^{4}$ em que a mirabilia é representada por uma criatura maléfica, apresenta uma rápida sequência de acontecimentos e pouca descrição, personagens planas,

2 "Pois aqui se tem de fato o elemento que distingue Märchen de uma legenda hagiográfica, por exemplo, em que um acontecimento maravilhoso desdobra profundo impacto sobre as personagens envolvidas, chegando a atuar assim enquanto verdadeiro milagre. Já nas narrativas dos Grimm, um sapo pode dirigir a palavra a uma princesa aflita, como em "O rei sapo ou o Henrique de ferro", ou uma outra princesa ("A Bela Adormecida”) pode despertar de um sono centenário, após ser beijada pelo príncipe, sem que ninguém veja nisso nada de assombroso.” (MAZZARI, 2014, p. 1255).

3 Para Todorov: “Existe um 'maravilhoso puro' que, assim como o estranho, não tem limites claros. No caso do maravilhoso, os elementos sobrenaturais não provocam qualquer reação particular nem no leitor, nem nas personagens, nem no leitor implícito. A característica do maravilhoso não é uma atitude, para os acontecimentos relatados a não ser a natureza mesma desses acontecimentos.” (1980, p.30) 4 O estatuto de conto popular tem sido questionado em relação a várias narrativas, pois estudos revelaram conteúdos intertextuais de livros nos relatos dos informantes orais dos Grimm, evidenciando que os contos publicados por Jacob e Wilhelm no primeiro volume dos Hausmärchen, em 1812, não eram originários da cultura iletrada. Rölleke e outros estudiosos, atentos às versões anteriores dessas histórias, concluíram que, quando se tratava de contos de fadas, as narrativas baseavam-se em livros lidos pelas jovens de Cassel no final do século XVIII e início do século XIX. No caso de Rumpelstilsequim, a fonte teria sido o conto Ricdin Ricdon de origem francesa, escrito por Marie-Jeanne L' Héritier no século XVIII (BOTTIGHEIMER, 2009, p. 50) 
uma perspectiva ingênua ${ }^{5}$ e fórmulas de linguagem; já o segundo, um conto maravilhoso moderno em que há um “objeto protetor” extraordinário (LE GOFF, 2002, p. 117). Colasanti, embora se utilize da estrutura, temas e personagens da literatura oral, como contos maravilhosos e mitos, insere questões contemporâneas em seus enredos. Dito de outra forma, suas narrativas vão além da fábula, os textos apresentam uma escritura definida, uma pluralidade de problemas e soluções (questões sociais e psicológicas) e reflexão crítica, perfazendo-se em um conto maravilhoso artístico, autoral e moderno.

Para a análise do conto Rumpelstiltsequim estabelecemos, neste estudo, um diálogo com Jack Zipes, por meio do artigo publicado pelo autor no periódico Western Folklore (1993, p. 43-60), Spinning with fate: Rumpelstiltskin and the decline of female productivity, no qual ele disserta sobre as implicações do desenvolvimento industrial na tradição fiandeira e como essa mudança é reverberada na variante redigida pelos Grimm em 1857.

Zipes (1993, p. 46) pontua como os folcloristas alemães se distanciaram da versão oral colhida em 1810, Rumpenstünzchen, minorando a importância do ofício de tecelã da protagonista do enredo original e valorizando as figuras masculinas da narrativa. Dessa maneira, o texto literário dos Brïder6 reflete as mudanças sociais que o advento da industrialização trouxe para o papel que a mulher representava na sociedade. A protagonista de Rumpelstilsequim não pode fazer escolhas. Primeiramente ela é coagida pelo pai a agradar ao rei transformando palha em ouro. Em seguida, vítima da ambição real, fica à mercê do poder do soberano. Por fim, a jovem rainha é chantageada pela estranha criatura. Nas duas versões, a filha do moleiro não tem conhecimento sobre a técnica de fiar, que tradicionalmente seria do âmbito feminino. A ela cabe gerar a descendência do rei.

Já o texto de Colasanti, publicado em 1982, na obra Doze reis e a moça no labirinto do vento, a moça tecelã, diferentemente da filha do moleiro, faz as suas próprias escolhas. A

5 A “ 'poesia ingênua', lembrando a sugestão feita por Friedrich Schiller em seu tratado Sobre poesia ingênua e sentimental [1795], quando toda a Natureza, da perspectiva do conto maravilhoso, entrava em cumplicidade com o ser humano para ajudá-lo a prevalecer sobre as forças colossais que se lhe opunham...” (MAZZARI, 2014, p. 1300).

6 Termo em alemão que significa irmãos, utilizado aqui para se referir aos irmãos Grimm. 
coerção que sofre do marido dura pouco tempo, porque a protagonista tem autonomia para desfazer o fio da história que ela mesma havia traçado. Como Penélope, "criatura criadora" (BARBOSA, 2013, p. 94), a moça tecelã tece o seu próprio destino rompendo com os padrões patriarcais do casamento.

Contudo, tanto no texto de Jacob e Wilhelm Grimm como no de Colasanti, o espaço diegético para as protagonistas está circunscrito à casa, a um ambiente fechado, podendo figurar a opressão patriarcal, como é usual nos romances góticos em que esse recurso simbólico é explorado de forma inventiva. De acordo com Sondgrass (2005, p. 96), o confinamento das heroínas é um dos motivos convencionais da literatura gótica. $\mathrm{O}$ tema derivaria de fontes mitológicas, como o mito grego de Perséfone aprisionada no submundo, e dos contos de fadas, como no caso de Rapunzel presa na torre. Tal artifício, nos romances góticos, acentuaria o terror das personagens causando-lhes claustrofobia e tormento mental. Para a crítica feminista, o enclausuramento em castelos, torres, abadias, masmorras e outros espaços cerrados seria uma metáfora do sufocamento social que paralisava e roubava a autorrealização das mulheres.

A casa da moça tecelã, primeiramente simples, torna-se, pela imposição masculina, um palácio. A filha do moleiro e a despretensiosa fiandeira de Marina Colasanti acabam tendo que circular num ambiente ainda mais restrito, sendo circunscritas à torre ou salas fechadas, onde devem cumprir o seu trabalho e ficam interditas ao ambiente externo. O lugar da ação é bastante significativo no que concerne à relação da mulher com o ambiente privado a partir do patriarcalismo.

A violência simbólica e exploratória sofrida pela protagonista de Colasanti, bem como a dos Grimm, reverbera as desigualdades de gênero construídas historicamente, em que a mulher é reputada como objeto de troca, um meio para garantir e perpetuar o poder dos homens.

O princípio da inferioridade e da exclusão da mulher, que o sistema mítico-ritual ratifica e amplia, a ponto de fazer dele o princípio de divisão de todo o universo, não é mais que a dissimetria fundamental, a do sujeito e do objeto, do agente e do instrumento, instaurada entre o homem e a mulher no terreno das trocas simbólicas, das relações de produção e reprodução do capital simbólico, cujo dispositivo central é o mercado matrimonial, que estão na base de toda ordem social: as mulheres só podem aí ser vistas como objetos, ou melhor, como símbolos cujo sentido se consti- 
tui fora dela e cuja função é contribuir para a perpetuação ou o aumento do capital simbólico em poder dos homens (BOURDIEU, 2002, s/n).

Em A moça tecelã, como em Rumpelstilsequim, a "violência simbólica" e a "estrutura de dominação" estão subjacentes às ações das personagens, demonstrando como o paradigma da sociedade patriarcal está enraizado no inconsciente dos homens e das mulheres. Na narrativa de Colasanti, as personagens, desprovidas de nomes próprios, são individualizadas por suas ações. A moça, trabalhadeira, dedica-se ao seu ofício: "Tecer era tudo o que fazia. Tecer era tudo o que queria fazer." (COLASANTI, 2006, p. 12). Com seu tear, ela fia o sol, a chuva, alimento, e o que beber, ou seja, ela produz o essencial para a sua sobrevivência. Por algum tempo, isso lhe bastou, até que, sentindo-se só, almejou um marido. Apesar da aparência principesca, o homem tecido em seu tear mostrou-se imperioso, interesseiro e mesquinho. A moça havia tecido um marido aos moldes do ideário patriarcalista e androcêntrico (ZOLIN et alii., 2007, p. 85). Conhecendo as possibilidades de riqueza que o tear poderia propiciar, o sonhado esposo colocou a tecelã ao seu serviço, ordenando-lhes caprichos. Esqueceu-se da vida compartilhada e dos filhos que juntos poderiam desfrutar. Por outro lado, o tear é tão valorizado que passa a ser humanizado pelo rapaz, enquanto a moça, julgada máquina, é coisificada: "Porque, descoberto o poder do tear, em nada mais pensou a não ser nas coisas todas que ele poderia lhe dar (COLASANTI, 2006, p. 12, grifo nosso).

É importante abrirmos um parêntese para compreender a passagem das sociedades matriarcais para a organização patriarcal a fim de ponderar sobre a situação das protagonistas dos textos em questão. Muraro (1991, p. 7-8) explica que, com a necessidade de cultivar a terra devido à escassez de alimentos, a humanidade deixou de ser nômade e se organizou em aldeias. Com o aumento da população e o desenvolvimento técnico, esses grupamentos foram se tornando mais complexos, estabelecendo cidades, cidades-estado, estados e impérios. Se nas sociedades que viviam da coleta e da caça de pequenos animais, a mulher podia dividir de maneira equilibrada a autoridade e dirigibilidade do grupo, com as mudanças nas atividades laborais, os valores passam a ser basear na lei do mais forte. $\mathrm{O}$ alimento produzido cabia ao dono da propriedade, sua família e seus escravos. Com o advento da agricultura, ter uma família numerosa e escravos garantia a mão-de-obra barata e a sobrevivência. Dessa forma, a 
sexualidade da mulher passou a ser controlada para assegurar a descendência e a transmissão da herança, ou seja, a dominação da terra. Doravante, a mulher ficou restrita ao âmbito doméstico. Devia deixar a casa paterna virgem e assegurar a posteridade do marido. $\mathrm{O}$ adultério passou a ser rigidamente punido. $\mathrm{O}$ espaço público e as decisões da sociedade, bem como os valores sociais, passaram a ser do domínio masculino. Dentre as atividades domésticas, incluiram-se a produção de têxteis que corroboraram com a permanência da mulher no interior do lar e com a economia familiar, mas sempre sob a vigilância da repressão masculina.

A reclusão das mulheres no interior das casas possibilitou que o excedente da produção redundasse em formas primitivas de acumulação de riqueza, o que, por sua vez, propiciava a ampliação dos domicílios, onde passou-se a reservar espaços próprios para a tecelagem. A invisibilidade da produção e das produtoras propiciava aos homens o ocultamento de sua dependência na produtividade feminina. Em contrapartida, esses espaços de manufatura estimularam os agrupamentos femininos. Juntas, as mulheres teciam e contavam histórias, propunham adivinhas e brincavam com a linguagem (MACHADO, 2003, p. 181).

A vinculação entre mulher, tear e matrimônio pode ser observada desde a Antiguidade, como no caso das representações dessa relação em vasos gregos antigos, especificamente em peças onde são retratadas cenas com fiandeiras e tecelãs. Por exemplo, no lécito de Amásis (LISSARRAGUE apud CARDOSO, 2006, p. 92-109), vaso grego datado de cerca de 540 a.C., que se encontra, hoje, no MAM de Nova Iorque, estão delineadas nove mulheres no processo de trabalho com a lã no corpo do vasilhame, enquanto na curva superior da envergadura em direção ao gargalo, há uma cena de dança. Lissarrague (apud CARDOSO, 2006 p. 94) avalia que a tecelagem e a dança são complementares, e, que, no imaginário grego havia certa analogia entre os movimentos das tecelãs e das dançarinas. Outro vaso semelhante foi encontrado junto ao lécito, e, nessa peça, um casamento está figurado. Em conclusão, o estudioso assevera que os dois objetos se complementam para descrever três atividades/momentos da vida da mulher: a dança, a tecelagem e o casamento. Os movimentos das figuras femininas se assemelham nos lécitos, o que viabiliza a leitura de Lisarrague: "[a] mulher segurando o fuso lembra a gesticulação de uma dançarina; o gesto de levantar o tecido, por sua vez, evoca o de uma noiva a levantar o véu." (CARDOSO, 2006, p. 94).

Rumpelstiltsequim, bem como a versão predecessora, Rumpenstünzchen, reflete alguns 
aspectos dessas práticas e desse universo feminino. As duas variantes tratam da falta de habilidade para tecelagem e como essa inadequação soa inusitada, pois tão singular e ridícula seria uma mulher não saber trabalhar com o fuso, que o descabido é retratado como se fora mais fácil produzir ouro do que desconhecer a arte da tecelagem. Outra referência dessa cultura fiandeira, presente nas duas versões, seria a adivinha, prática usual entre as tecelãs enquanto trabalhavam. No conto em questão, a adivinhação se refere ao nome da criatura mágica, que aliás, também faz uma brincadeira com a linguagem, já que se trata de um nome inusitado e de difícil pronúncia. Zipes afirma que Rumpelstiltskin se insere num conjunto de histórias em que a inabilidade ou aptidão para a produção têxtil são parte do enredo, bem como há contos em que as adivinhas e brincadeiras com a linguagem são inseridas na narrativa. Em "As três fiandeiras" (GRIMM, 2014, p. 153-155), por exemplo, uma garota preguiçosa é impelida pela mãe a fiar vários quartos cheios de linho para a rainha. Se assim o fizesse, ela poderia se casar com o príncipe. Com a ajuda mágica das três fiandeiras, que transformam toda a matéria prima em linha, a protagonista casa-se com o filho da rainha e livra-se, de uma vez por todas, do trabalho de tecelã.

Ainda de acordo com Jack Zipes (1993, p. 43), é estranho que folcloristas, psicanalistas e críticos literários tenham se detido na questão do nome e do papel de Rumpelstilsequim, embora o nome, em si, não tenha nenhum significado, pois não revela nada sobre a essência da criatura. O nome serve apenas como artifício para banir o homenzinho mágico da vida da rainha. Além disso, a função dessa personagem teria sido sempre apresentada de forma equivocada. Por exemplo, em Thompson (1977 p. 47), Rumpelstiltskin é categorizado como um ajudante, quando ele é obviamente um opressor ou chantageador. Em resumo, Zipes (1993, p. 43) considera que o problema específico colocado pela história seria a opressão feminina em relação às mudanças sociais referentes ao trabalho têxtil e a iniciação feminina no mundo adulto e do trabalho. Certamente a versão dos irmãos Grimm reflete os aspectos e mudanças econômico-sociais coetâneos, no entanto, não acreditamos que esse seja o cerne do conto em questão. A presença de um ajudante mágico, que é também o antagonista da narrativa, bem como a mudança da condição social da protagonista são os motivos centrais do enredo.

A adivinhação está relacionada a enigmas e jogos presentes em diversas tradições orais de diferentes culturas. Quando a rainha adivinha o nome do duende, há certo alívio cômico, 
pois aponta-se para uma disposição otimista da história demonstrando como a fiandeira ultrapassou os obstáculos e se deu conta dos desejos e propósitos de sua vida. Nomear alguém ou alguma coisa relaciona-se também com a ideia de obter poder sobre algo que antes era desconhecido (DUARTE JR.,1988, p. 43). Ao nomearmos, (re)conhecemos, o que nos dá capacidade para nos proteger. Assim, é apropriado que a tecelã nomeie aquilo que lhe causa problemas e identifique seus inimigos. Apesar do nome Rumpelstilsequim não apresentar um significado revelador, o ato de nomear é crucial para o desfecho do conflito na narrativa.

Quando nos textos bíblicos menciona-se que "No princípio era o Verbo, e o Verbo estava com Deus, e o Verbo era Deus” (João 1:1, 2008, p. 1386) está implícita a ideia de que nomear as coisas é fazê-las existir. Assim, por meio da linguagem aprendo e entendo a multiplicidade do mundo. "Quando nomeio alguma coisa, eu a apreendo e, de certa forma, adquiro poder sobre ela, ao encerrá-la em minha mente através do símbolo que a representa” (DUARTE JR.,1988, p. 43-44). O autor também chama atenção para os rituais de exorcismo, pois, durante o processo, é importante que se saiba o nome do demônio que se apoderou do sujeito para poder expurgá-lo (DUARTE JR., 1988, p. 43-44). Da mesma forma, em Rumpelstilsequim, a rainha só pode sobrepujar o poderio da criatura quando lhe conhece o nome.

A humanidade tem necessidade de exercer controle sobre a natureza, nesse sentido, as classificações e nomenclaturas servem para atribuir significados. Ana Maria Machado (2003, p. 173-174) comenta sobre esse imperativo ao narrar sua experiência com a filha depois de testemunhar o momento da tessitura de uma teia por uma aranha de jardim. Esse comentário da autora antecipa as discussões posteriores que faz sobre Rumpelstilsequim, pois nesse conto é notória a relação entre nomear e ter controle, sendo esse um dos temas importantes para o desenvolvimento da narrativa e da personagem. A filha do moleiro precisa tecer o seu destino seja por meio da roca ou das palavras. Como observou a autora, a história da filha do moleiro se liga a um longo fio da tradição: as Parcas, Penélope, Ariadne, Aracne, a bruxa da Bela Adormecida, entre outras personagens femininas que tecem e destecem destinos - fio esse que também se emaranha com a "A moça tecelã", de Marina Colasanti.

Para Zipes (2012, p. 95), conforme citação abaixo, os contos de fada falam mais verdades do que os adultos gostariam de saber, fixam-se em nossas mentes e, possivelmente, em nossas almas também. São histórias otimistas, já que apresentam desfechos felizes e cujos mundos 
apresentam mais justiça social que o nosso. Essas histórias, iniciadas desde que a humanidade adquiriu a capacidade de se comunicar, versariam sobre o conhecimento e a experiência adquiridos e vividos no âmbito social. Para ele o aspecto maravilhoso dos contos que nos parece tão extravagante não se diferenciaria de algumas crenças e religiões atuais, igualmente fantasiosas.

We ward off fairy tales and pretend that they are intended mainly for children because they tell more truth than we want to know, and we absorb fairy tales because they tell us more truth than we want to know. They are filled with desire and optimism. They drip with brutality, bluntness, violence and perversity. (...). They stamp our minds and perhaps our souls. They form another world, a counter world, in which social justice is more readily attainable than in our actual world, where hypocrisy, corruption, hyping, exploitation and competition determine the outcome of social and political interactions and the degraded state of social relations. Though it is impossible to trace the historical origins and evolution of fairy tales to a particular time and place, we do know that humans began telling tales as soon as they developed the capacity of speech (ZIPES, 2012, p. 95).

Dessa forma, o autor desconsidera as análises de cunho psicanalítico, nas quais se assevera que os mitos e contos de fadas expressam processos inconscientes, atendo-se, portanto, a uma crítica mais materialista. Entendemos que não é possível recusar a ideia de que nas narrativas tradicionais são reproduzidas, de forma singular, a profundidade e a força das imagens míticas. E que somente a linguagem simbólica dos mitos e dos contos maravilhosos dá conta de expressar a rede de sentidos imbricadas em nosso inconsciente (VON FRANZ, 1985, p. 3). Dito de outra maneira, quando Zipes interpreta o sentido de fantasioso com base no contexto histórico social, ele atenua, ao nosso ver, o conteúdo simbólico do conto:

Podemos dizer que há certas estruturas básicas do comportamento psicológico que pertencem à espécie humana em geral e outras mais desenvolvidas em um grupo ou raça e menos predominantes em outros. Os contos de fadas têm uma estrutura que reflete traços humanos mais gerais. Desempenham um grande papel e porque através do estudo dos contos de fada e mitos podemos vir a conhecer certos complexos 
estruturais, tornando-nos mais capazes de distinguir entre o que é e o que não é individual, e ver as possíveis soluções (VON FRANZ, 1985, p. 3).

Para entender o ponto de vista do estudioso, vale lembrar que Zipes trabalhou com a versão de 1857 dos irmãos Grimm comparando-a com a variante oral de 1810 registrada em Ölenberg, Rumpenstünszchen. O crítico considera-o como um conto de fadas literário, pois nele se aliam variantes folclóricas com a tradição literária francesa, especificamente, com Ricdin-Ricdon, de Mlle. L. Héritier (1798). Enquanto a variante oral refletiria a tradição das contadoras de histórias, as quais eram provavelmente fiandeiras, as histórias orais do século XVII e XVIII foram submetidas a transformações literárias ao mesmo tempo em que a produção têxtil sofria uma transformação significante com a industrialização da Grã-Bretanha e do continente europeu. Ao compararmos Rumpenstünzchen (1810) com Rumpelstilsequim (1857), notamos que (conscientemente ou não) os Grimm fizeram uma apresentação histórico-social da exploração das mulheres como fiandeiras e da apropriação da arte de fiar pelo homem.

O professor norte-americano elencou as principais mudanças nas versões para desenvolver a sua interpretação. Na variante de 1810, há apenas uma jovem camponesa cujo problema é a incapacidade de transformar linho em tecido. Ao tecer, ela transforma a matéria prima em ouro. Já na versão tardia, o pai da jovem camponesa se gaba de a filha ser capaz de transformar palha em ouro. Quando o homenzinho faz a proposta de fiar em troca do primeiro filho para a camponesa da primeira versão, ela rapidamente aceita a barganha mesmo com as condições apresentadas; já a protagonista da segunda, reluta, mas, como o rei a ameaça de morte caso não faça a mágica da conversão em ouro, ela cede. Em Rumpenstüzchen, a jovem envia uma criada para descobrir o nome do ser mágico e em Rumpelstilsequim, a rainha envia um serviçal. Descoberto seu nome, a criatura foge em uma concha (1810). Na versão de 1857, o duende se parte em dois e desaparece embaixo da terra.

Zipes (1993, p. 49-50) conclui que os Grimm alteraram a versão de Rumpenstünzchen de maneira que o valor da arte de fiar e a autonomia da jovem fiandeira são enfraquecidos. Preocupados com a elaboração literária do conto, os irmãos procuraram incluir uma motivação mais clara, e uma transição mais fluída e lógica para o enredo. Na variante de 1857, a filha do moleiro está totalmente à mercê do poder masculino dos homens, toda a sua vida é 
modelada por homens: o pai fanfarrão, o rei opressor, Rumpelstilsequim, o chantagista, e o criado salvador. A única coisa que ela é capaz de fazer é dar à luz uma criança. Para o século XIX, a boa mulher era a mulher que sabia o seu lugar, e o conto trata de uma mulher que é colocada em seu lugar por homens. A versão literária dos Grimm (1857) faz da presença masculina algo crucial para determinar a situação e o destino da filha do moleiro, enquanto em Rumpenstünzchen, a jovem decide seu próprio destino em conflito com os homens.

Claro está que os contos vão sofrendo alterações de acordo com as condições sócio históricas e ideológicas da época, basta compararmos as versões dos contos de fadas produzidas pela Disney na metade do século XX com as contemporâneas. Não obstante, mesmo sofrendo tais adulterações, as histórias geralmente contêm uma essência que se sobressai e é o que faz com que ela permaneça sendo contada com o passar do tempo. O estudo de Jack Zipes (1993, p. 43-60) é muito elucidador no que tange às relações entre as versões literárias dos contos de fada e a sociedade dos séculos XVIII e XIX, em que fica clara a tendência patriarcalista e a passagem da técnica artesanal de tecer das mãos das tecelãs para a dos homens e das máquinas, visando maior lucro. Contudo, mesmo na versão anterior, Rumpenstünzchen, embora as mulheres dominem a arte e a produção tecelã, isso não as coloca numa posição de autonomia, pois, nesse período, as mulheres já estavam confinadas no lar produzindo excedentes para a economia familiar, e não para sustento próprio. Se lermos a variação mais antiga do conto levando em conta a relação histórico-social, podemos interpretar a vitória da mulher sobre a criatura, que tem mais habilidade para tecer do que ela, como sendo compensatória. Ademais, a permanência de determinadas ações nas duas narrativas indica que a essência dos contos em questão é a iniciação de uma jovem para o trabalho e o casamento, ou seja, a iniciação para a maturidade, que só é alcançada quando derrota o antagonista, ou seja, quando descobre a denominação do homenzinho e nomeia seu opositor. Por outro lado, com base na versão literária dos Grimm, infere-se que não só a produção têxtil feminina estava em declínio, mas a própria participação das mulheres como narradoras. A voz das contadoras de histórias fiandeiras é enfraquecida, pois a lógica masculina e burguesa a sobrepõe. Nesse sentido, vencer o opositor por meio da palavra seria um desfecho esperançoso ou reparador.

Uma leitura de cunho histórico-social sem dúvida propicia uma reflexão sobre a relação entre o desenvolvimento do capitalismo e as questões de gênero, mas não é possí- 
vel abandonar a perspectiva de que a narrativa compreende um aspecto simbólico, o qual condensa sua essência na questão da adivinhação do nome da criatura que chantageia a filha do moleiro. O mistério do nome implica na incapacidade que a personagem tem, no início, de resolver seus problemas, demonstrando certa imaturidade. Ao nomear o homenzinho, a rainha supera as suas fraquezas e inabilidades, pois foi por meio de seus esforços e astúcia que o nome é, enfim, desvelado. Rumpelstilsequim não tem um significado explícito porque pode configurar qualquer inaptidão, dificuldade ou carência que a personagem deve suplantar. Dessa forma, os ouvintes ou leitores podem se identificar com a protagonista correspondendo o nome da criatura a um desafio que lhe seja próprio, o que torna o conto amplamente significativo.

Com suas histórias maravilhosas, Marina Colasanti resgata e mantém viva a importância da narrativa como uma forma de possibilitar a troca de experiências. As histórias, com seu conteúdo arquetípico e metafórico, ensinam mais sobre a humanidade do que uma notícia que se esgota na imediatez da novidade (BENJAMIN, 2012, p. 216). Assim, o conto da moça tecelã fala muito mais sobre a experiência feminina em sua luta contra a sociedade patriarcal do que uma notícia veiculada pelo jornal ou outra mídia. A narrativa permanece viva porque não se consome na novidade e na verificabilidade da informação, formada por sucessivas camadas, ela é capaz de desdobrar-se, atualizando-se.

A moça tecelã dialoga com o mito de Penélope no sentido em que destecer é mais importante para o desenvolvimento da narrativa e da personagem do que tecer. De acordo com a leitura de Heilbrun (1990, s/n, apud MACHADO, 2003, p. 188), Penélope é a primeira personagem feminina a fazer uma escolha. Afinal, ela poderia desposar um dos pretendentes se desejasse. Ela opta por esperar, seja na esperança do retorno do marido ou por preferir ficar só. Heilbrun aponta para o sentido metafórico do tecer e destecer como a construção da própria vida, testando possibilidades. A moça tecelã também é uma personagem que, com os fios do tear, os fios da sua vida nas mãos, tece o seu destino. Mas as escolhas não são feitas apenas de subjetividades, pois as coerções sociais acabam por influenciar as ações. Talvez por isso, a moça que desejava apenas tecer, quis um marido, pois de acordo com uma visão burguesa e androcêntrica, ela só se completaria por meio do casamento e da constituição de uma família. Dessa maneira, ela se deixa dominar porque não ainda não possui a experiência ou uma visão 
crítica a respeito da dominação que lhe é exercida. Aceita viver uma relação amorosa pautada pela violência exercida por meio do controle das ações, da exploração econômica e da perda da autonomia. Contrariamente a Penélope ${ }^{7}$, percebe que já não tece para si mesma, que o destino que está fiando não atende os seus desejos, mas aos desejos do outro, anulando-se.

A violência simbólica se institui por intermédio da adesão que o dominado não pode deixar de conceder ao dominante [...] quando ele não dispõe, para pensá-la e para se pensar, ou melhor, para pensar sua relação com ele, mais que de instrumentos de conhecimento que ambos têm em comum e que, não sendo mais que a forma incorporada da relação de dominação, fazem esta relação ser vista como natural; ou em outros termos, quando os esquemas que ele põe em ação para se ver e se avaliar, ou para ver e avaliar os dominantes (elevado/baixo, masculino/feminino, branco/ negro etc.), resultam da incorporação de classificações, assim naturalizadas, de que seu ser social é produto (BOURDIEU, 2007, p. 47).

Zolin et alii (2007, p. 92) assinalam como Colasanti consegue trabalhar num plano simbólico incorporando elementos da contemporaneidade. $\mathrm{O}$ marido, além de reverberar atitudes autoritárias de cunho patriarcal, enfatizadas pela escolha dos verbos dicendi - exigir, ordenar e advertir -, reproduz a lógica capitalista de produção e acumulação de riquezas por meio da exploração do trabalho. Nesse sentido, são introduzidos advérbios - logo, imediatamente - para denotar a necessidade de acelerar o trabalho da jovem, de modo que produza como uma máquina, para com mais "pressa" propiciar muitas "coisas".

Ainda segundo essas autoras (2007, p. 91), o conto renunciaria aos finais tradicionais dos contos de fadas, 'E foram felizes para sempre' e teria um movimento circular de início e retorno, ou seja, ao destecer o marido e voltar a ficar sozinha, a moça voltaria a sentir-se solitária e voltaria a tecer uma companhia. No entanto, para falar com Bettelheim (1980, p.18), o "felizes para sempre" dos contos maravilhosos não significaria uma felicidade ad infinitum,

7 E ainda que não se dê a ênfase a isso na narrativa homérica, Penélope, com sua criação silenciosa, dita regras e ordena universos, enquanto o amante, em sua árdua trajetória de retorno é marionete dos deuses (...). A mulher protege Ítaca da ruína... (BARBOSA, 2013, p. 66). 
mas o sentido mesmo da plenitude que a personagem alcança no momento em que a ação narrada termina. A felicidade seria o momento de completude alcançada pela personagem na relação com o outro, ou, acrescentaríamos, consigo mesma. Claro está que, se a vida dos protagonistas continuasse a ser narrada, outros conflitos desequilibrariam esse estado de deleite.

'E viveram felizes para sempre' - não engana a criança nem por um momento quanto à possibilidade de vida eterna. Mas indica realmente a única coisa que pode extrair o ferrão dos limites reduzidos do nosso tempo nesta terra: construir uma ligação verdadeiramente satisfatória com outra pessoa. Os contos ensinam que quando uma pessoa assim o fez, alcançou o máximo, em segurança emocional de existência e permanência de relação disponível para o homem; e só isto pode dissipar o medo da morte. Se uma pessoa encontrou o verdadeiro amor adulto, diz também o conto de fadas, não necessita desejar a vida eterna. Isto é sugerido por outro final muito comum: "Eles viveram por um longo tempo, felizes e satisfeitos" (BETTELHEIM, 1980, p. 18).

A moça alcança a sua felicidade ao tornar-se mais madura. Assim como na história da rainha de Rumpelstilsequim, o obstáculo foi vencido, e a sabedoria da vida apreendida. No caso da personagem de Colasanti, quebrar os padrões patriarcais impostos e livrar-se da opressão masculina opera uma mudança de âmbito subjetivo e social. Poderíamos dizer que a moça tecelã procura, no sentido proposto por Giddens (1993, p. 68), um "relacionamento puro" e, por isso, quando sentiu que o marido não corresponderia ao que havia almejado, destece as linhas que os emaranhava e decide ficar só.

O termo 'relacionamento', significando um vínculo emocional próximo e continuado com outra pessoa, só chegou ao uso geral em uma época relativamente recente. Para esclarecer o que está em jogo aqui, podemos introduzir a expressão relacionamento puro para nos referir a este fenômeno. Um relacionamento puro não tem nada a ver com pureza sexual, sendo um conceito mais restritivo do que apenas descritivo. Refere-se a uma situação em que se entra em uma relação apenas pela própria relação pelo que pode ser derivado por cada pessoa da manutenção de uma associação com outra, e que só continua enquanto ambas as partes considerarem que extraem dela satisfações suficientes, para cada um individualmente, para nela permanecerem. Para 
a maior parte da população sexualmente 'normal', o amor costumava a ser vinculado à sexualidade pelo casamento, mas agora os dois estão cada vez mais vinculados através do relacionamento puro (GIDDENS, 1993, p. 68-69).

Refletindo sobre os aspectos simbólicos que permeiam os mitos e contos que versam sobre o ofício feminino de tecer, é importante lembrar que os instrumentos que servem para a produção têxtil são símbolos do destino. Dessa maneira, podemos inferir que, para as moças dos contos em questão, tecer é criar formas novas. As duas conseguem superar os desafios impostos pelo destino e pelas próprias escolhas. Como aranhas que constroem as teias a partir da própria substância, extraem de si mesmas o estímulo para tecer e destecer o destino (CHEVALIER, 1986, passim).

Por outro lado, na urdidura dos destinos estão imbricadas as coerções sociais e, enquanto a filha do moleiro não consegue se desenredar das intrincadas linhas do patriarcalismo, a moça tecelã destece um enredo que, equivocadamente, parecia naturalizado. 


\section{Referências}

BARBOSA, Giliard Ávila. Nas tramas de outra Odisseia: as tessituras míticas em Viajes de Penélope, de Juana Rosa Pita. 2013. 115f. Dissertação (Mestrado em Letras), Universidade Federal do Rio Grande, Rio Grande, 2013.

BENJAMIN, Walter. Magia e técnica, arte e política: ensaios sobre literatura e história da cultura. Trad. Sérgio Paulo Rouanet. 8. ed. revista, São Paulo: Brasiliense, 2012.

BETTELHEIM, Bruno. A psicanálise dos contos de fada. Trad. Arlene Caetano. 17. ed., Rio de Janeiro: Paz e Terra, 1980.

BÍBLIA. João. In: BÍBLIA Sagrada. Tradução: João Ferreira de Almeida. Barueri, SP: Sociedade Bíblica de Aparecida, 2008.

BOTTIGHEIMER, Ruth B. Fairy tale: a new history. Albany, New York: State Universitu of New York Press, 2009.

BOURDIEU, Pierre. A dominação masculina. Trad. Maria Helena Kühner. 2. ed., Rio de Janeiro: Bertrand Brasil, 2002.

CARDOSO, Zélia de Almeida. O artesanato feminino em Roma e os textos antigos: fiandeiras e tecelãs. Calíope: presença clássica. Programa de Pós-Graduação em Letras Clássicas, Faculdade de Letras - UFRJ. Rio de Janeiro: 7 letras, 14, p. 92-109, 2006,

CHEVALIER, Jean (dir.). Diccionario de los símbolos. Barcelona: Editorial Herder, 1986.

COELHO, Nelly Novaes. O conto de fadas: símbolos, mitos, arquétipos. São Paulo: Paulonas, $e-b o o k$. 
COLASANTI, Marina. Doze reis e a moça do labirinto do vento. São Paulo: Global, 2006.

DUARTE JR., João Francisco. Fundamentos estéticos da educação. 10. ed., Campinas, SP: Papirus, 1988.

GRIMM, Irmãos. Os contos de Grimm. Trad. Tatiana Belinky. 2. ed., São Paulo: Paulus, 2014.

GRIMM, Irmãos. Príncipes, princesas e rainhas nos contos de Grimm: seleção da edição Contos maravilhosos infantis e domésticos 1812-1815 [E-book] (Locais do Kindle 1255-1258). Cosac Naify. Edição do Kindle, 2014.

GRIMM, Jacob. Contos dos irmãos Grimm. Organizado, selecionado e prefaciado pela Dra. Clarice Pinkola Estés. Trad. de Lia Wyler. Rio de Janeiro: 2005, p. 297-299.

LE GOFF, Jacques. Maravilhoso. In: LE GOFF, Jacques; SCHMITT, Jean Claude (coord). Dicionário Temático do Ocidente Medieval. 2 vol. Bauru, SP: EDUSC; São Paulo: Imprensa Oficial do Estado, 2002.

MACHADO, Ana Maria. O Tao da teia: sobre textos e têxteis. In: Estudos Avançados, São Paulo, v. 17, n. 49, p. 173-196, dez. 2003. Disponível em: http://www.scielo.br/scielo.php? script=sci_arttext\&pid=S0103-40142003000300011\&lng=en\&nrm=iso. Acesso em: 27 Nov. 2016.

MAZZARI, Marcus. O homem bicentenário de um clássico: poesia do maravilhoso em versão original. In: GRIMM, Irmãos. Príncipes, princesas e rainhas nos contos de Grimm: seleção da edição Contos maravilhosos infantis e domésticos 1812-1815 [E-book] (Locais do Kindle 1255-1258). Cosac Naify. Edição do Kindle, 2014.

MURARO, Rose Marie. Breve introdução histórica. In: KRAMER, Heinrich; SPRENGER, James. O martelo das feiticeiras: malleus maleficarum. Trad. Paulo Fróes. 4. ed., Rio de Janeiro: Rosa dos Ventos, 1991. 
ROAS, David. A ameaça do fantástico: aproximações teóricas. Trad. Julián Fuks. São Paulo, Unesp, 2014.

THOMPSON, Stith. The folktale. Los Angeles, California: University of California Press, 1977.

VON FRANZ, Marie-Louise. A sombra e o mal nos contos de fada. Trad. Maria Christina Penteado Kujawski. São Paulo: Paulus, 1985.

ZIPES, Jack. Spinning with Fate: Rumpelstiltskin and the Decline of Female Productivity. In: Western Folklore, vol. 52, no. 1, 1993, pp. 43-60. 7STOR, www.jstor.org/stable/1499492, pp. 43-60. A fairy tale is more than just a fairy. BTWO $2(1+2)$ pp. 95-102 Intellect Limited, 2012. ZOLIN, Lúcia Osana; JACOMEL, Mirele Carolina; PAGOTO, Cristian; MOLINARI, Soraya. Violência Simbólica e Estrutura de Dominação em A Moça Tecelã, de Marina Colasanti. In: Graphos. João Pessoa, v. 9, n. 2, p. 81-93, 2007. 